\title{
REVIEW \\ Resistance Genes and Selection DNA Markers for Blast Disease in Rice (Oryza sativa L.)
}

\author{
Yohei KOIDE ${ }^{2}$, Nobuya KOBAYASHI ${ }^{2}$, Donghe $\mathrm{XU}^{1}$ and Yoshimichi FUKUTA ${ }^{1 *}$ \\ ${ }^{1}$ Biological Resources Division, Japan International Research Center for Agricultural Sciences \\ (Tsukuba, Ibaraki 305-8686, Japan) \\ ${ }^{2}$ Genetic and Biotechnology Division, International Rice Research Institute \\ (DAPO Box 7777, Metro Manila, Philippines)
}

\begin{abstract}
Blast is a serious disease caused by a fungal pathogen Pyricularia oryzae Cavara of rice (Oryza sativa L.). The use of resistant varieties is considered one of the most efficient ways of crop protection from the disease. In addition to a large amount of information accumulated during the long history of genetic studies on resistance to rice blast, recent progress in rice genomics has enabled us to use DNA markers for breeding the resistant varieties by marker assisted selection (MAS). In this report, we summarize the reported rice blast resistance genes and their selection markers to encourage further utilization for breeding. First, we assemble the information about the reported genes with regard to their number, chromosomal locations, patterns of resistance, donor strains, and molecular characterization of the cloned genes by reviewing the literature. In addition, we present some remaining issues about the nomenclature system and identification of the resistance genes. Then, we provide the first assembled list of the reported DNA markers for blast resistance genes, including the sequences of the primer pairs, genetic distances from the resistance genes, and cross combinations of the parental strains used to detect the polymorphisms. This information will help rice breeders to improve the resistance to rice blast by MAS.
\end{abstract}

Discipline: Plant breeding

Additional key words: Blast (Pyricularia oryzae Cavara), marker assisted selection (MAS), resistance gene

\section{Introduction}

Blast is a serious disease caused by a fungal pathogen Pyricularia oryzae Cavara of rice (Oryza sativa L.). It causes considerable damage to rice and crop loss in rice growing regions worldwide ${ }^{6,60,79}$. Although fungicides can be used to control rice blast, they generate additional costs in rice production and chemical contamination of environment and foods. Therefore, the use of resistant varieties is thought to be one of the most economically and environmentally efficient ways of crop protection from the disease.

A large amount of information has been accumulated during the long history of genetic studies on resistance to rice blast. In addition, recent progress in rice genomics will facilitate using the resistance genes in breeding by
DNA marker assisted selection (MAS). However it is not easy for breeders to handle a large amount of information for DNA markers and there are no reports or databases that assemble reported marker information for rice blast resistance genes. In this report, we summarize the reported resistance gene information for rice blast and their selection markers. Such information will help rice breeders improve the resistance to rice blast through using MAS.

\section{Overview of blast resistance genes}

Since the first publication of the inheritance of host resistance to rice blast ${ }^{89}$, many reports of the resistance genes for rice blast have been published. To date, more than 70 genes and 347 quantitative trait loci (QTLs) have been detected ${ }^{2}$. To encourage further utilization of these

*Corresponding author: e-mail zen@affrc.go.jp

Received 29 September 2008; accepted 23 January 2009. 
resistance genes for marker-assisted rice breeding, we first summarize this large amount of information. Although there have been many QTL mapping studies for rice blast resistance, it is still unclear whether many QTLs with minor effects can be used in marker-assisted breeding. Thus we will focus on only genes or QTLs with major effects in this review.

\section{Number of rice blast resistance genes}

The genes and major QTLs responsible for the rice blast resistance are listed in Table 1. To date, 96 genes or major QTLs have been reported. Among the reported resistance genes, several gene symbols are synonymously used for the following two reasons.

(1) The gene symbols were revised in accordance with the international committee on gene symbolization in 1995 (e.g., Pib and Pis, Pita and Pi4, Piz and Pi2, and, Pil1 and Pizh).

(2) The genes are suggested to be identical to each other based on their reaction pattern to blast isolates and/or linkage analysis (e.g. Pi3(t) and Pi5(t), and Pil and $\left.\operatorname{Pi}(\mathrm{t})^{45,49}\right)$.

In addition, several genes are suggested to be allelic or tightly linked (e.g., Pi2/Piz, Piz-t, and Piz-5 on chromosome 6, Pik, Pik-s, Pik-p, Pik-m, Pik-h, and Pik-g on chromosome 11, and Pita and Pita-2 on chromosome 12).

\section{Characterization of the cloned resistance genes}

As of now, nine resistance genes, $\mathrm{Pib}^{102}$, Pita, Pik- $h^{90}, P_{i} 9^{87}, P_{2} 2^{114}, P_{i z} t^{114}, P_{i d}{ }^{14}, P i 36^{16}$, and Pi3 $37^{64}$ have been isolated and cloned using map-based cloning strategies.

Eight of the cloned genes (Pib, Pita, Pik-h, Pi9, Pi2, Piz-t, Pi36, and Pi37) have the sequences including both nucleotide binding site (NBS) and leucine-rich repeat (LRR) domains, which are contained by the commonest class of plant resistance gene $e^{4,32,42}$. The products of the NBS-LRR domain containing resistance genes seem to interact with the avirulence (Avr) gene of the pathogen and follow a gene-for-gene type resistance. Jia et al. ${ }^{51}$ showed that the product of the Avr gene for Pita, Avr-Pita, binds specifically to the LRR domain of the Pita protein by the yeast two hybrid system and an in vitro binding assay. This suggests that the product of the resistance gene, Pita, binds directly with the effecter gene product of the pathogen to initiate the resistance gene mediated defense response. However, it is still unknown whether the other resistance genes also interact with the pathogen directly.

Another cloned resistance gene, Pid2, encodes a receptor-like kinase protein with a predicted extracellular domain of a bulb-type mannose specific binding lectin (Blectin $)^{14}$. Because of its novel extracellular domain, Pid2 represents a new class of plant resistance gene.

\section{Location of the resistance genes}

To summarize the locations of the rice blast resistance genes in the genome a genetic map with the positions of the reported genes was constructed (Fig. 1). The map position was based on the high-density genetic map constructed by the Rice Genome Program ${ }^{12,33}$. The approximate genetic positions of the resistance genes were determined by identifying BAC or PAC clones that contained the sequences of the cloned gene or the flanking marker.

Many reports mention that the genes affecting blast resistance are colocalized on chromosomes 6, 11 and $12^{7,103}$. On chromosome 6, at least 14 genes and/or alleles (Pi2, Piz, Piz-t, Piz-5, Pi8(t), Pi9, Pi13, Pi13(t), $P i 25(\mathrm{t}), P i 26(\mathrm{t}), \operatorname{Pi27}(\mathrm{t}) \operatorname{Pid2}, \operatorname{Pigm}(\mathrm{t})$, and $P i 40(\mathrm{t}))$ have been mapped in the region near the centromere. Among them, Pi2, Piz-t, and Pi9 are cloned and confirmed to be in the same genomic region. They are embedded in a gene cluster containing tandemly repeated NBS-LRR genes $^{87,114}$. Zhou et al. ${ }^{114}$ revealed that Pi2 and Piz- $t$ are allelic and eight amino acid changes differentiate between them.

On the long arm of chromosome 11, at least nine genes (Pi1, Pi7, Pi18, Pif, Pi34, Pi38, Pi44(t), PBR, and Pilm2) and six alleles at the Pik locus (Pik, Pik-s, Pik-p, $P i k-m, P i k-h$, and $P i k-g$ ) have been mapped. Hayashi et al. ${ }^{39}$ revealed that three alleles of the Pik locus, Pik, Pik-p and $P i k-m$ are mapped on the same chromosomal region by linkage analysis using 300 to $2,100 \mathrm{~F}_{2}$ segregation populations. Although this result is consistent with the notion that these three genes are multiple alleles at the one locus, more detailed analysis is necessary to confirm that they are allelic. Sharma et al..$^{0}$ identified and cloned the $P i k$ - $h$ gene from an Indica-type variety, Tetep. However its location is apart from the Pik cluster. The question whether the cloned Pik-h gene from Tetep is the same gene as the Pik-h gene first reported by Kiyosawa and Murty $^{56}$ is under debate ${ }^{106}$.

On chromosome 12, at least 17 resistance genes and/or alleles (Pita, Pita-2, Pitq6, Pi6(t), Pi12(t), Pi12(t), Pi19(t), Pi20(t), Pi21(t), Pi24(t), Pi31(t), Pi32(t), Pi39(t), $P i 62(\mathrm{t}), P i 157(\mathrm{t}) I P i$, and $I P i 3)$ have been mapped in the region near the centromere (the gene symbol, Pi12(t) is used for the different two genes as mentioned below).

Based on the data of genome-wide mapping of the NBS-LRR domain containing genes reported by Monosi et al. ${ }^{72}$, all three clusters of the rice resistance genes are closely associated with the clusters of NBS-LRR domain 


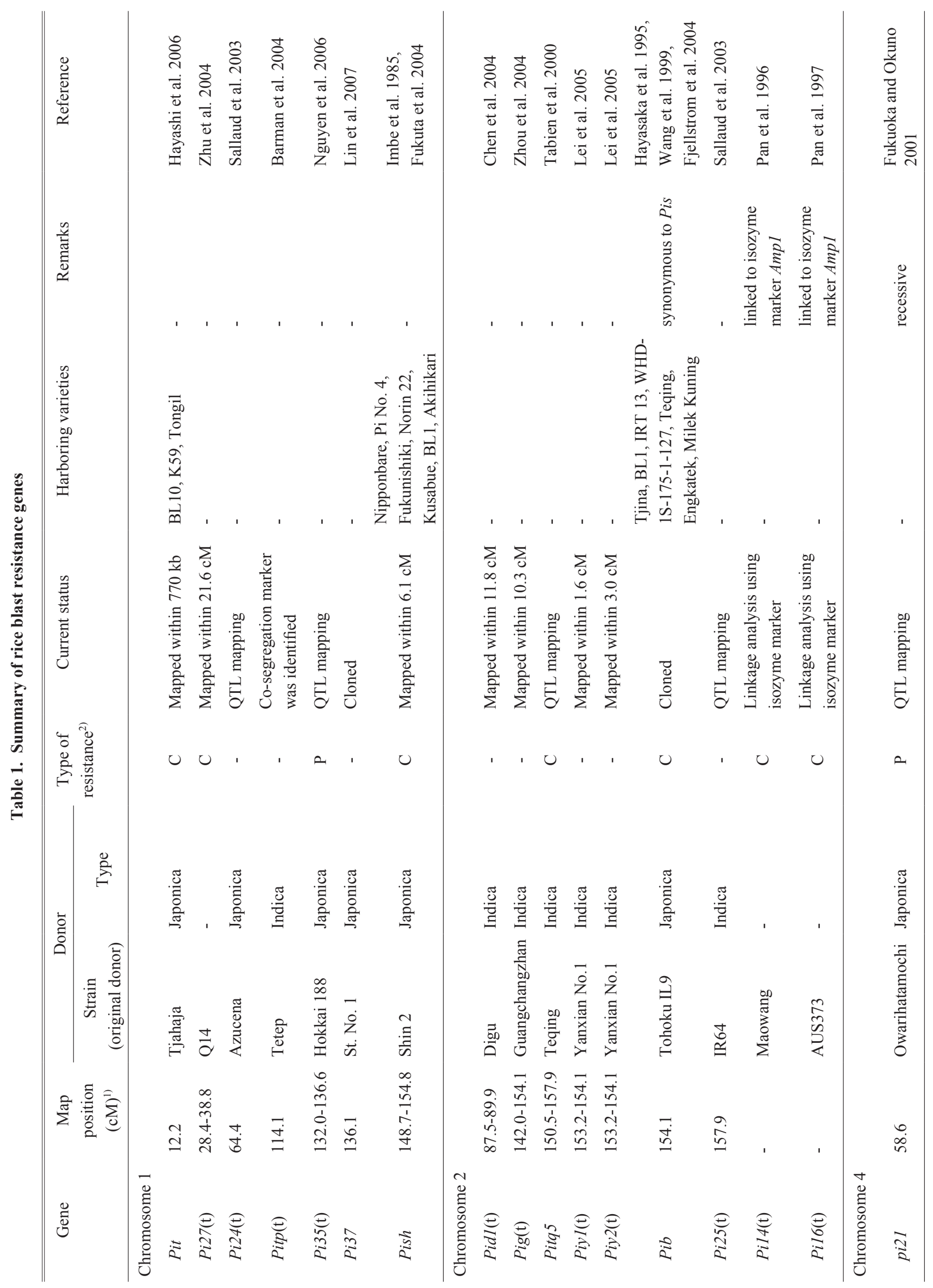




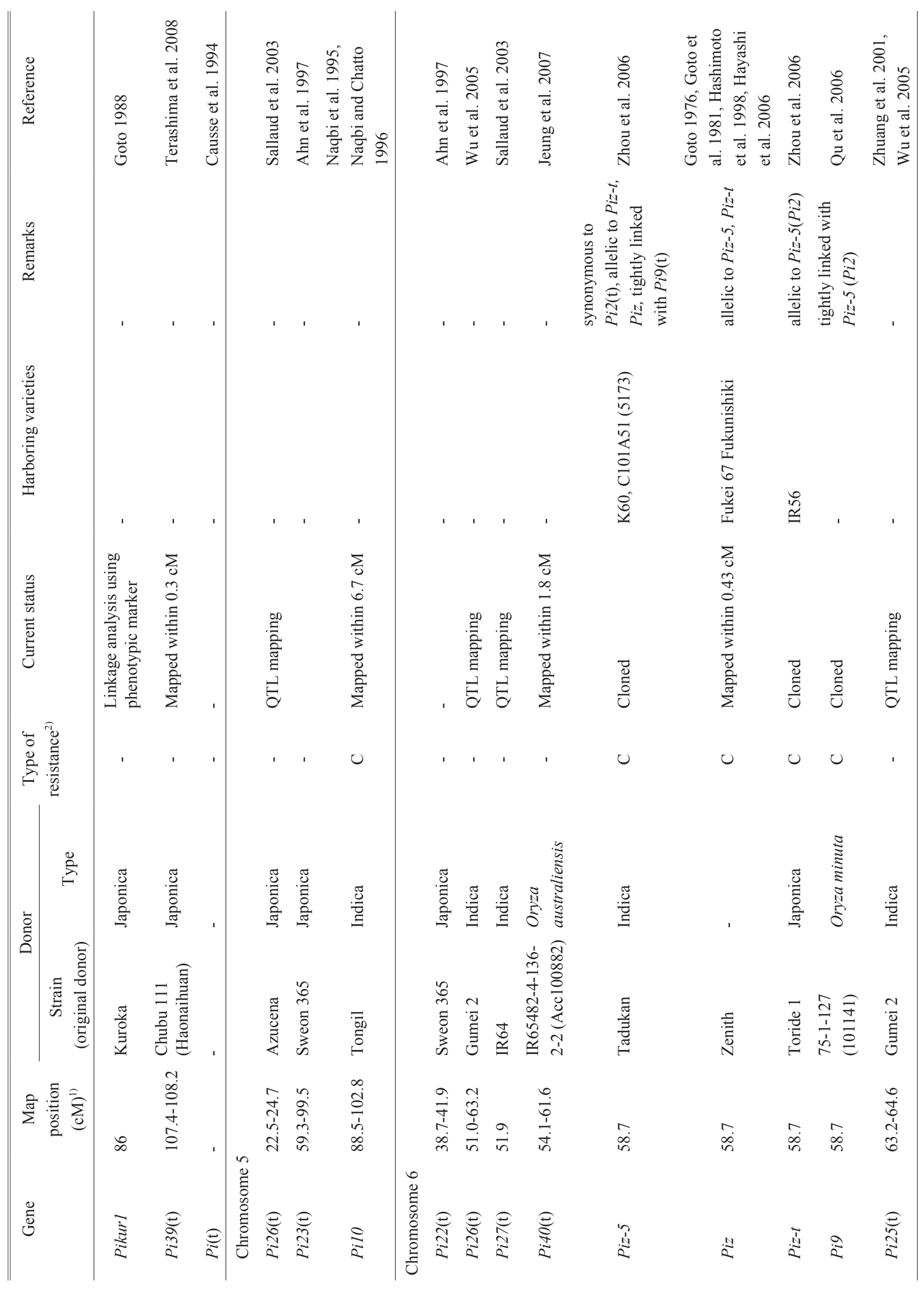


Resistance Genes and Selection Markers for Blast Disease in Rice

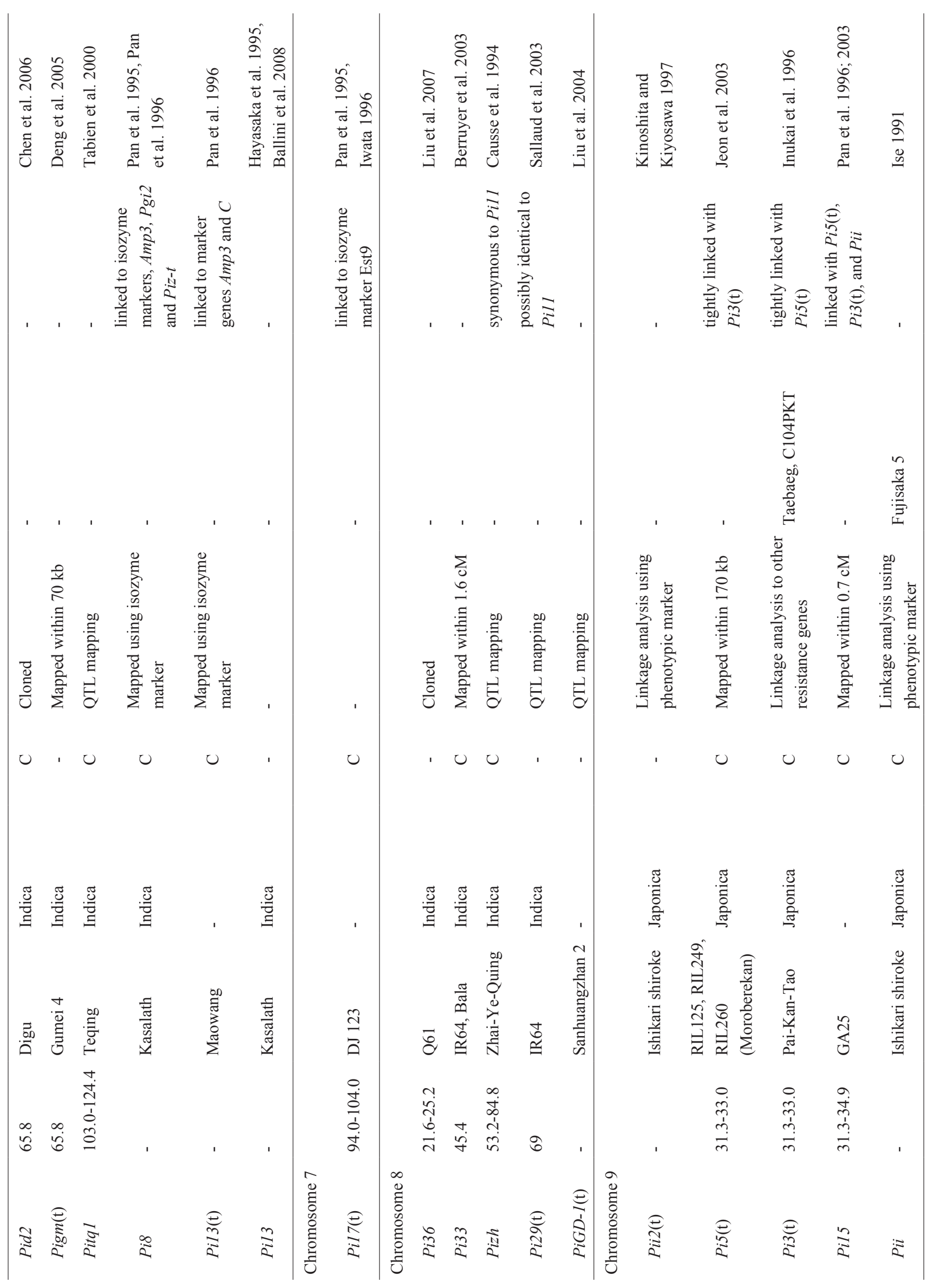




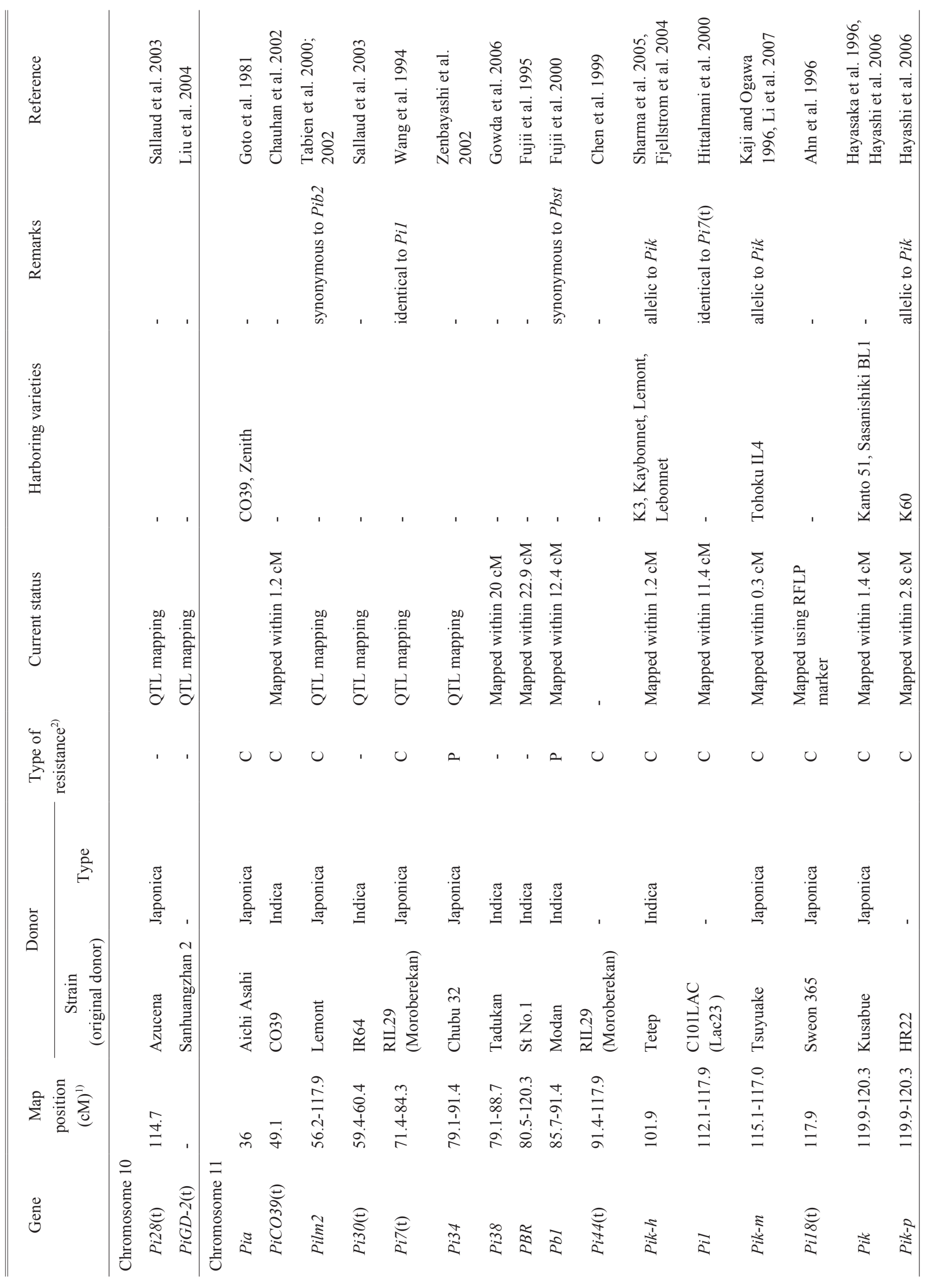


Resistance Genes and Selection Markers for Blast Disease in Rice

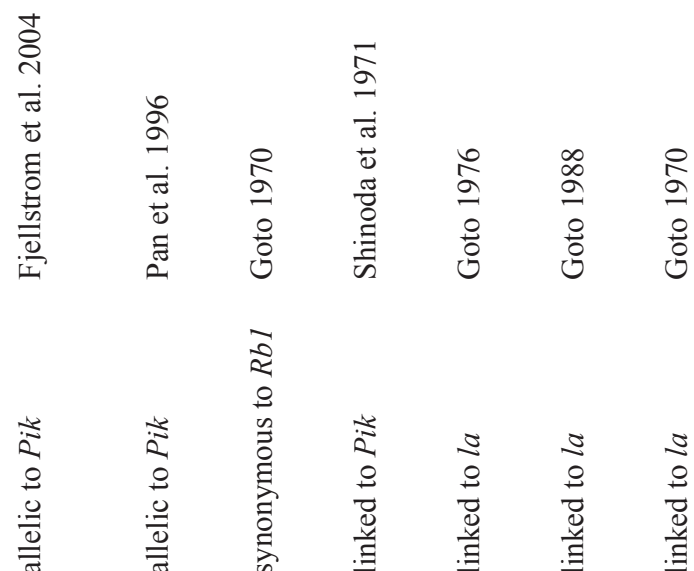

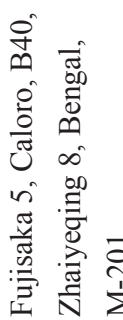

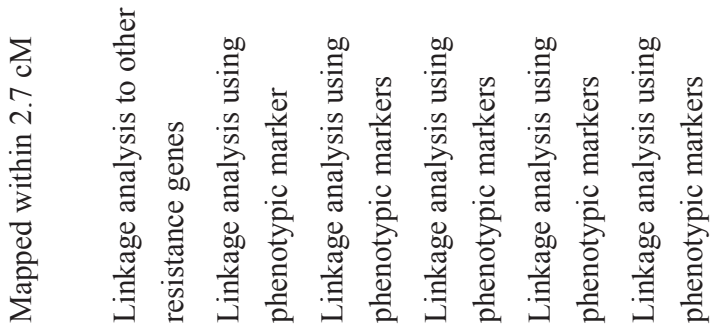

o 0 , a

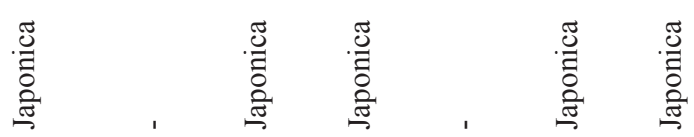

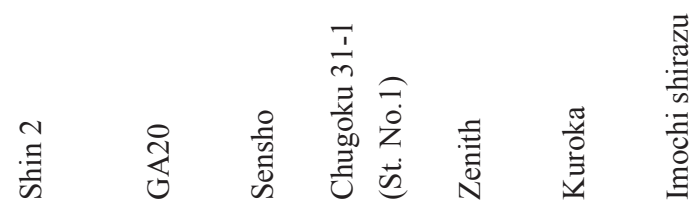

$\stackrel{?}{\stackrel{2}{\leftrightarrows}}$

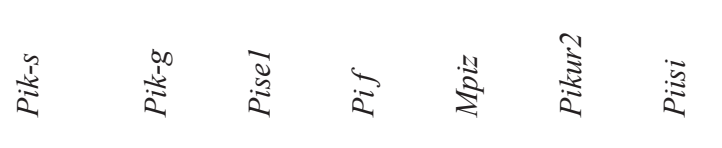

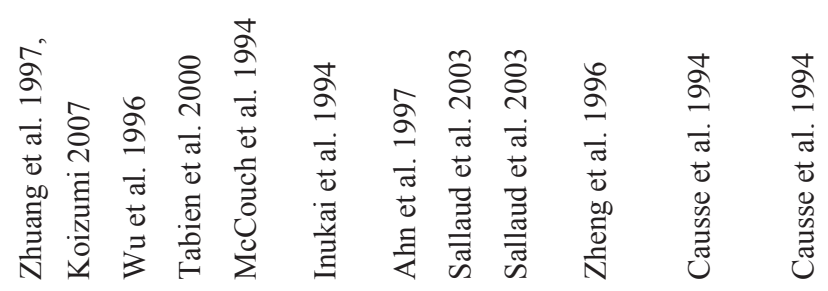

$\frac{\pi}{2}$

$\frac{\sqrt{4}}{\sqrt[4]{a}}$

i

言苍

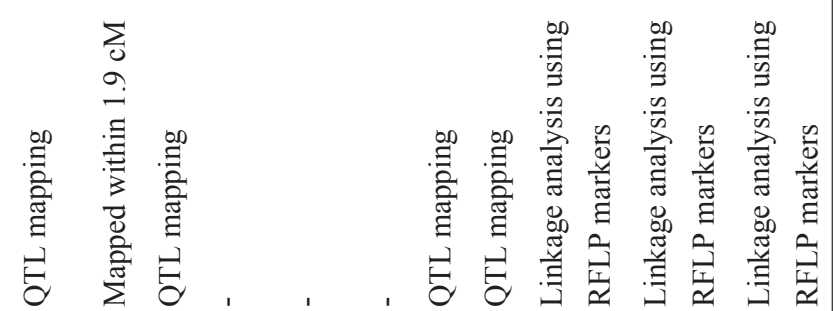

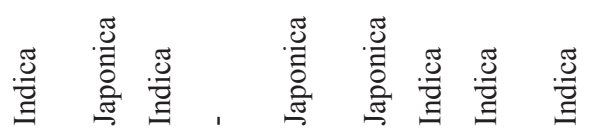

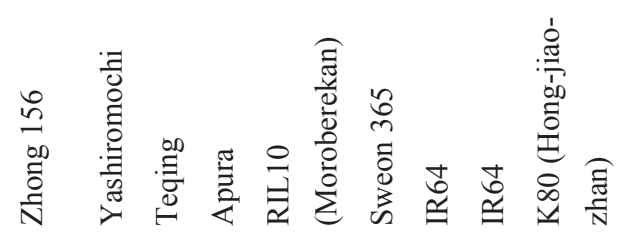

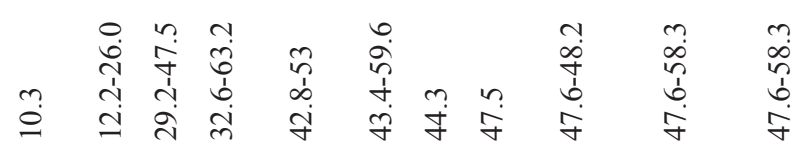

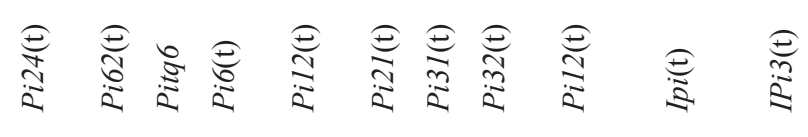




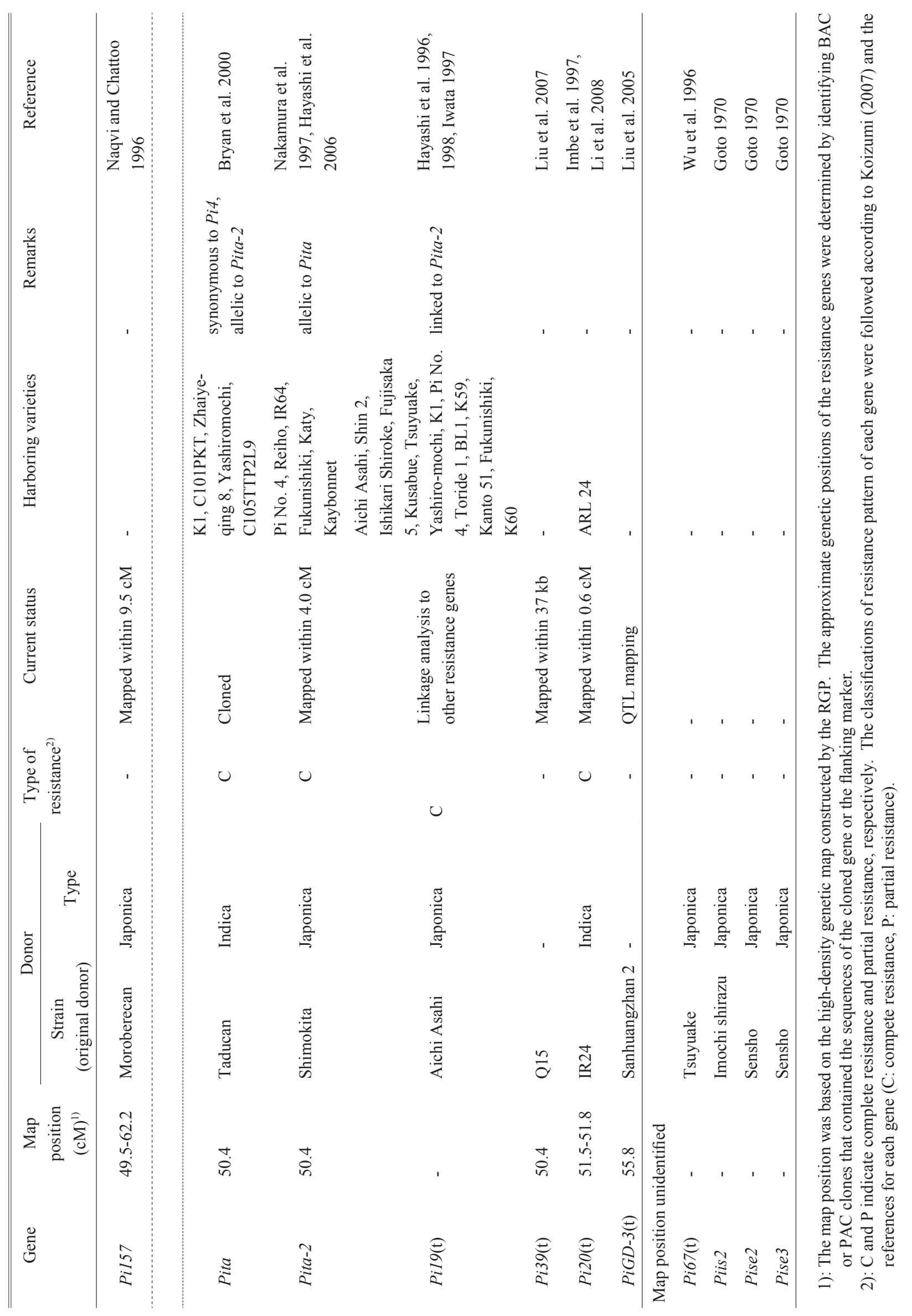



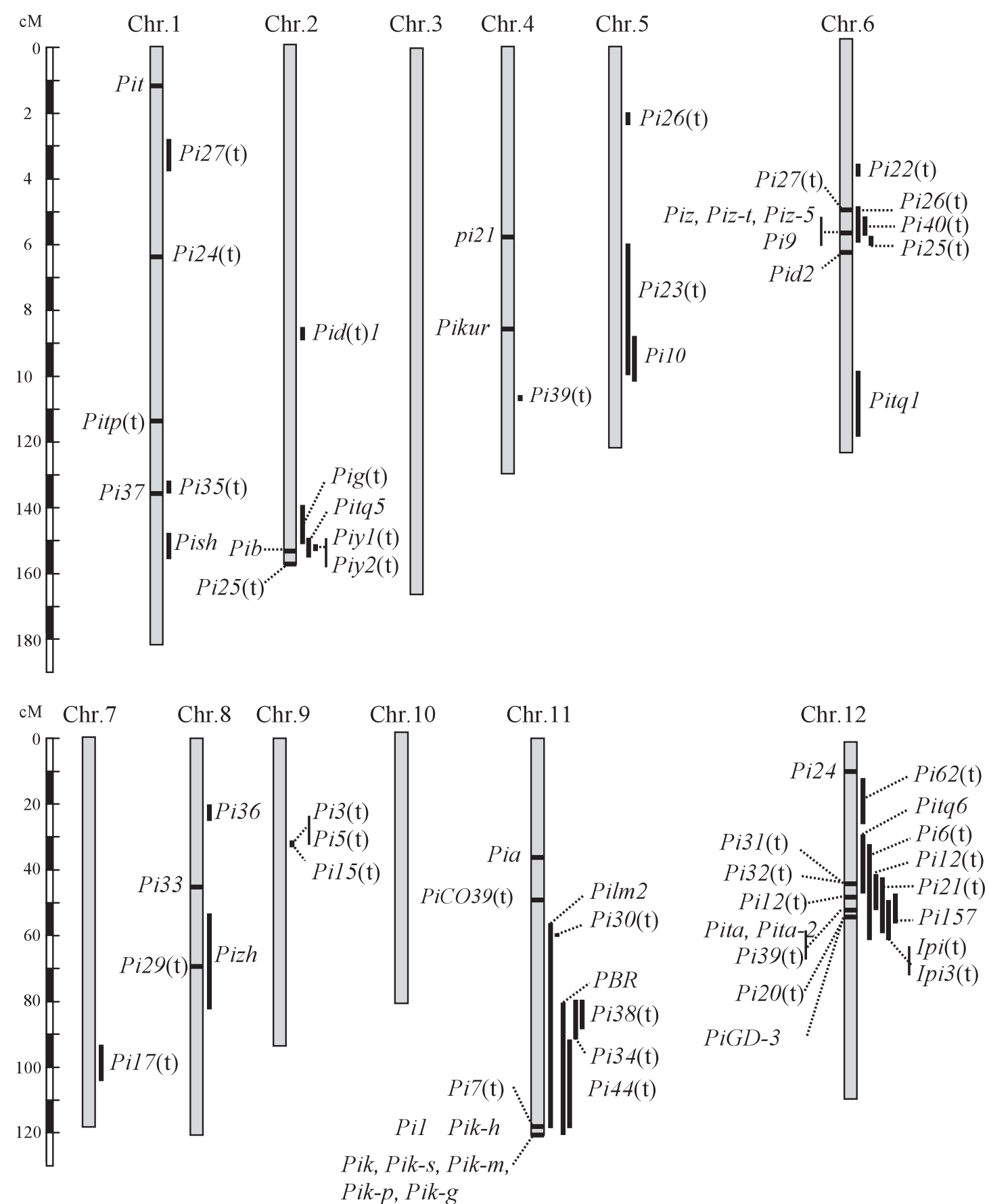

Fig. 1. Putative location of the blast resistance genes reported by 2008

The genetic location of each gene is based on the public databases (Oryzabase and Gramene) and the references for each gene (see Table 1).

containing genes. Ballini et al. ${ }^{2}$ also reported that $80 \%$ of the complete resistance genes for rice blast colocalize with NBS-LRR candidates. These data suggest that nonrandom distribution of the resistance genes is partly due to localization of the NBS-LRR domain containing genes in the genome.

\section{Partial resistance}

Blast resistance in rice is generally classified into complete and partial resistance. Complete resistance, caused by incompatible combinations between the host and pathogen strains, prevents reproduction of the pathogen, and the resistance is usually controlled by a major gene. Another form of resistance, partial resistance, 
is characterized by a decrease in the extent of pathogen reproduction in the compatible interaction ${ }^{86}$. Although the partial resistance has been thought to be under polygenic control and shows a non pathogen race specific pattern of resistance, several recent studies suggest that not all the partial resistance have such characteristics. To date, four major genes (Pif, pi21, Pb1, and Pi34(t)) that control partial resistance are reported (Table 1) $)^{19,21,110-112}$ Moreover, Zenbayashi-Sawata et al. ${ }^{112}$ reported that the interaction between the partial resistance gene Pi34(t) and a corresponding avirulence gene follows the gene-forgene model, suggesting that the partial resistance gene does not always show a non pathogen race specific pattern of resistance.

The molecular mechanism of the partial resistance genes is one of the topics for studying resistance genes. Fukuoka et al. ${ }^{22,23}$ revealed that one of the partial resistance genes, pi21, has sequences different from those of the previously reported complete resistance genes. Recently, Ballini et al. ${ }^{2}$ revealed that the reported QTLs for partial resistance are different from the mapped complete resistance genes with regard to colocalization with resistance gene analogs by meta-QTL analysis, which statistically estimates the position of one single QTL by combining the QTL obtained from different studies. These results were consistent with the notion that partial and complete resistance is governed by different types of genes.

\section{Donor strains}

Apart from three resistance genes (Pi9, Pi33 and Pi40(t)) that have been found in wild relatives, most rice blast resistance genes have been found in rice blast resistant varieties. Tsunematsu et al. ${ }^{99}$ revealed that an Indica-type variety, CO 39, which has been used as a susceptible check strain also carried the rice blast resistance gene, Pia, and made a monogenic line harboring it. In addition, Chauhan et al. ${ }^{9}$ showed that $\mathrm{CO} 39$ also carried another blast resistance gene, $\operatorname{PiCO} 39(\mathrm{t})$. These observations suggest that even a variety previously considered to be susceptible might have the resistance gene which specially interacts with the unidentified isolates and is used as a donor parent of the resistance genes.

Telebanco-Yanoria et al. ${ }^{95}$ surveyed genetic diversity of blast resistance in 922 rice varieties by using the standard differential blast isolates selected by TelebancoYanoria et al. ${ }^{96}$. They revealed the relationships among the variations of the pattern of resistance for 20 standard blast isolates, geographical distribution, and the genetic variations characterized by the isozyme type ${ }^{26}$ of the rice varieties. Such a study will help to find a novel resistance gene and enhance the diversity of the resistance genes used in rice breeding.

\section{Problems in studying blast resistance genes}

\section{Nomenclature system}

As shown in Table 1, 96 rice blast resistance genes have been reported. Information about these genes is available in databases such as Oryzabase (http://www. shigen.nig.ac.jp/rice/oryzabase/top/top.jsp) and Gramene (http://www.gramene.org/). However, the following problematic points remain to be solved.

(1) The same gene symbol was given to different genes as Ballini et al. ${ }^{2}$ pointed out. There are at least 9 redundant gene symbols, $P i 12, P i 13$, Pi14, Pi21, Pi24, Pi25, Pi26, Pi27, and Pi39, that have been used to date.

(2) Several studies do not follow the rules for naming and symbolization of blast resistance genes. If a blast resistance gene is identified, it should be designated with $P i$ followed by a numeral according to the Committee on Gene Symbolization $^{54}$.

(3) Different studies use different writing systems for the same resistance gene (e.g., Pik-h, Pikh, $P i-k h, P i k^{h}$, and $\left.P i-k^{h}\right)$.

The rice blast research community should have responsibility for symbolizing a new gene to avoid a confusing situation.

\section{Identification of the genes}

As mentioned above, several gene symbols are synonymously used because they are suggested to be identical with each other based on their reaction pattern to blast isolates and/or linkage analysis (e.g., Pi3(t) and $P i 5(\mathrm{t})$, and Pil and $\left.P i 7(\mathrm{t})^{45,49}\right)$. However, it is difficult to confirm the identification of the two genes, because if both the genes are dominant and tightly linked to each other, it is impossible to confirm that these genes are identical to each other by a simple allelism test. Similarly, although many of the resistance genes have been mapped on the same chromosomal region and are thought to be in a gene cluster, it is still unclear whether these genes are at tightly linked different loci or whether these genes are the alleles of one locus. Furthermore, several genes are suggested to be allelic without detailed confirmation of the allelic relationships in some cases. Information about whether the two genes are allelic is important for breeding because the alleles of one locus cannot be integrated into and fixed in one plant, while two genes at different loci can. More detailed analysis, such as high resolution mapping and positional cloning of the genes, is necessary to confirm the allelic relationship of the genes. 
Except for the tightly linked genes, genetic analysis based on gene segregation is a powerful tool for clarifying the identity of the genes. Toriyama et al. ${ }^{98}$ demonstrated that the estimation of genes with resistance to blast in rice varieties by using segregation analysis with the population derived from a cross between resistant and susceptible varieties was effective. Monogenic lines for blast resistance were developed as the first set of international standard differential varieties ${ }^{25,58,99}$. Such a differential system is very useful to estimate the identity of the genes by conventional segregation analysis.

\section{Using MAS for blast resistance genes}

\section{Advantages of molecular markers for selecting resistance genes}

Marker assisted selection (MAS) is a process whereby a DNA marker is used for indirect selection of the genes underlying target traits. With the fast development of molecular biotechnologies, MAS has been receiving more attention in recent years because it has advantages for efficiency and effectiveness as compared to conventional phenotypic selection (reviewed by Collard et al. ${ }^{15}$; Xu and Crouch $^{105}$ ). There are several advantages of using MAS for breeding instead of using conventional phenotypic selection. For example, MAS has the potential to save time and reduce the cost of breeding in cases where conventional phenotypic selection is particularly timeconsuming or expensive to measure. Furthermore, selection based on DNA markers may be more reliable due to the influence of environmental factors on field trials.

MAS has been shown to be especially valuable in backcross breeding. Over $90 \%$ of the recurrent parental genotype can be recovered within two generations when a suitable number of markers (e.g., one marker every 10 $\mathrm{cM}$ ) and an adequate number of progeny are used for background selection ${ }^{94,105}$. Since the complete resistance to rice blast is often controlled by a major gene, MAS seems useful for improving the complete resistance to rice blast by backcross breeding. In addition, MAS is a powerful tool for pyramiding two or more genes affecting blast resistance. In some cases, the phenotypic effect of the resistance gene is masked by that of another resistance gene, which is brought together into one plant, because blast resistance genes sometimes confer resistance to overlapping spectra of blast pathotypes. In this case, it is difficult to monitor the presence of multiple resistance genes without using MAS.

\section{Markers suitable for MAS}

Many types of DNA markers including restriction fragment length polymorphisms (RFLPs), random amplified polymorphic DNAs (RAPDs), amplified fragment length polymorphisms (AFLPs), simple sequence repeats (SSRs), and cleaved amplified polymorphic sequences (CAPS), have been developed ${ }^{71}$. Among them, PCR markers, such as CAPS and SSRs require only small quantities of DNA from small tissue samples for genotyping. Therefore selection can be carried out at the seedlings stage. Thus these markers are cost-effective and advantageous for applied breeding.

Recently, Hayashi et al. ${ }^{39}$ developed a PCR-based marker system for 9 rice blast resistance genes based on the information of single-nucleotide polymorphisms (SNPs) and small insertions/deletions (InDels). In this system, by using allele-specific PCR primers, the genotypes of SNP can be easily assessed according to the presence or absence of PCR-amplified products. Because SNPs and small InDels are highly abundant and widely dispersed throughout the genome in rice ${ }^{17,77,108}$, such types of DNA markers can help generate a sufficient number of markers within target genomic regions.

\section{Conventional markers developed for detecting rice blast resistance genes}

To date, 9 of the rice blast resistance genes have been isolated by map based cloning and more than 14 genes have been finely mapped (Table 1). During the procedure of fine mapping of the resistance genes, DNA markers which are tightly linked to or co-segregated with the target genes can be obtained. These markers have the potential for use in MAS. In addition, several markers have been developed based on the information of the cloned resistance gene position ${ }^{18,39,52,59}$. These markers were designed according to DNA polymorphisms between resistant and susceptible varieties within or around the genes.

The PCR based markers reported to be tightly linked or co-segregated with the rice blast resistance genes are listed in Table 2. Although there are many reports of genetic linkage analysis using RFLP or AFLP markers, we excluded these types of markers from the list because RFLP or AFLP are laborious to use in a breeding program. Information for these conventional markers will encourage further utilization of the resistance genes for marker-assisted rice breeding.

\section{Future perspectives of MAS for blast resistance genes}

Because MAS uses DNA markers to indirectly select the phenotype, its efficiency is highly dependent on the strength of association between using DNA markers and genes responsible for the phenotypes. If there is a DNA 


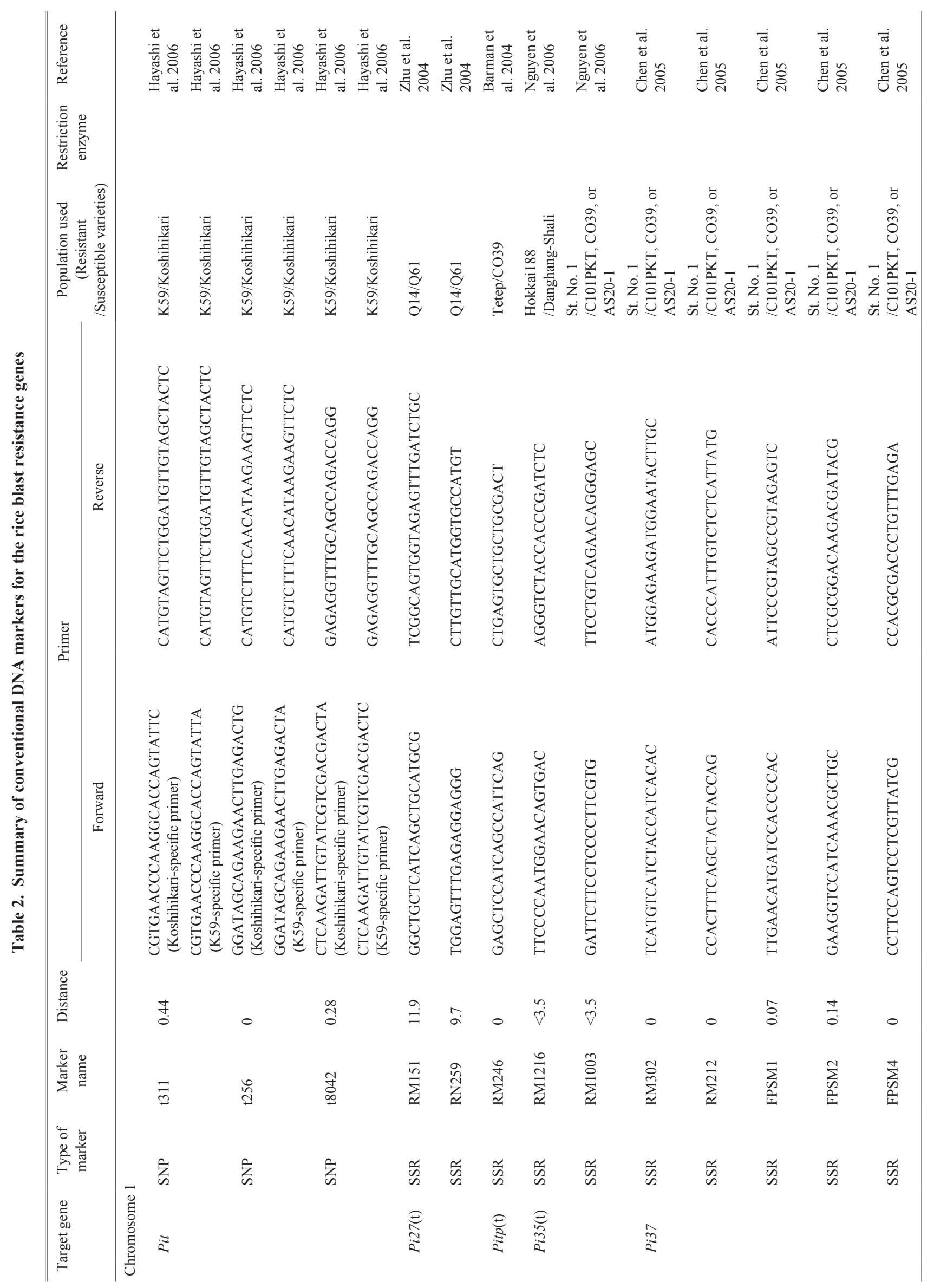




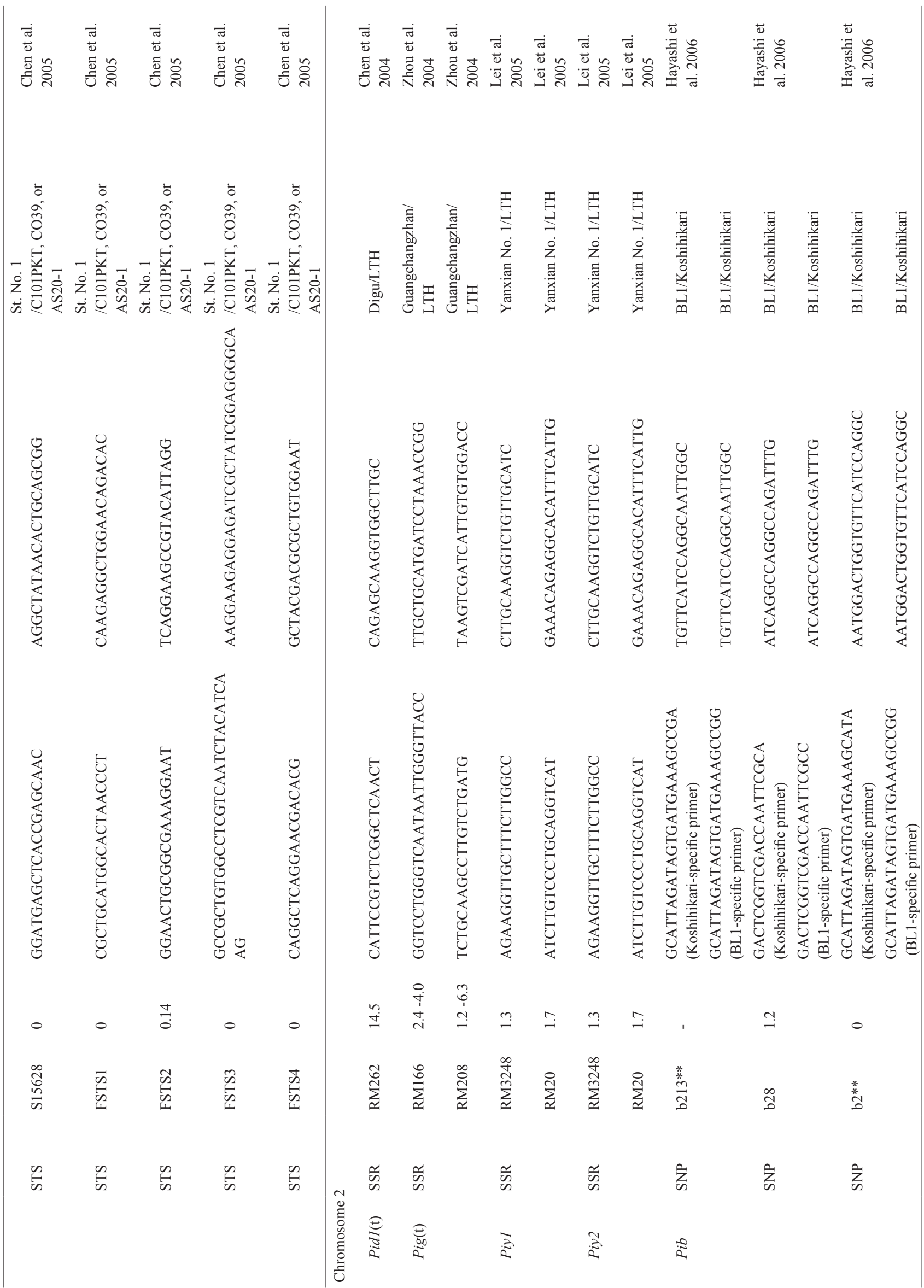




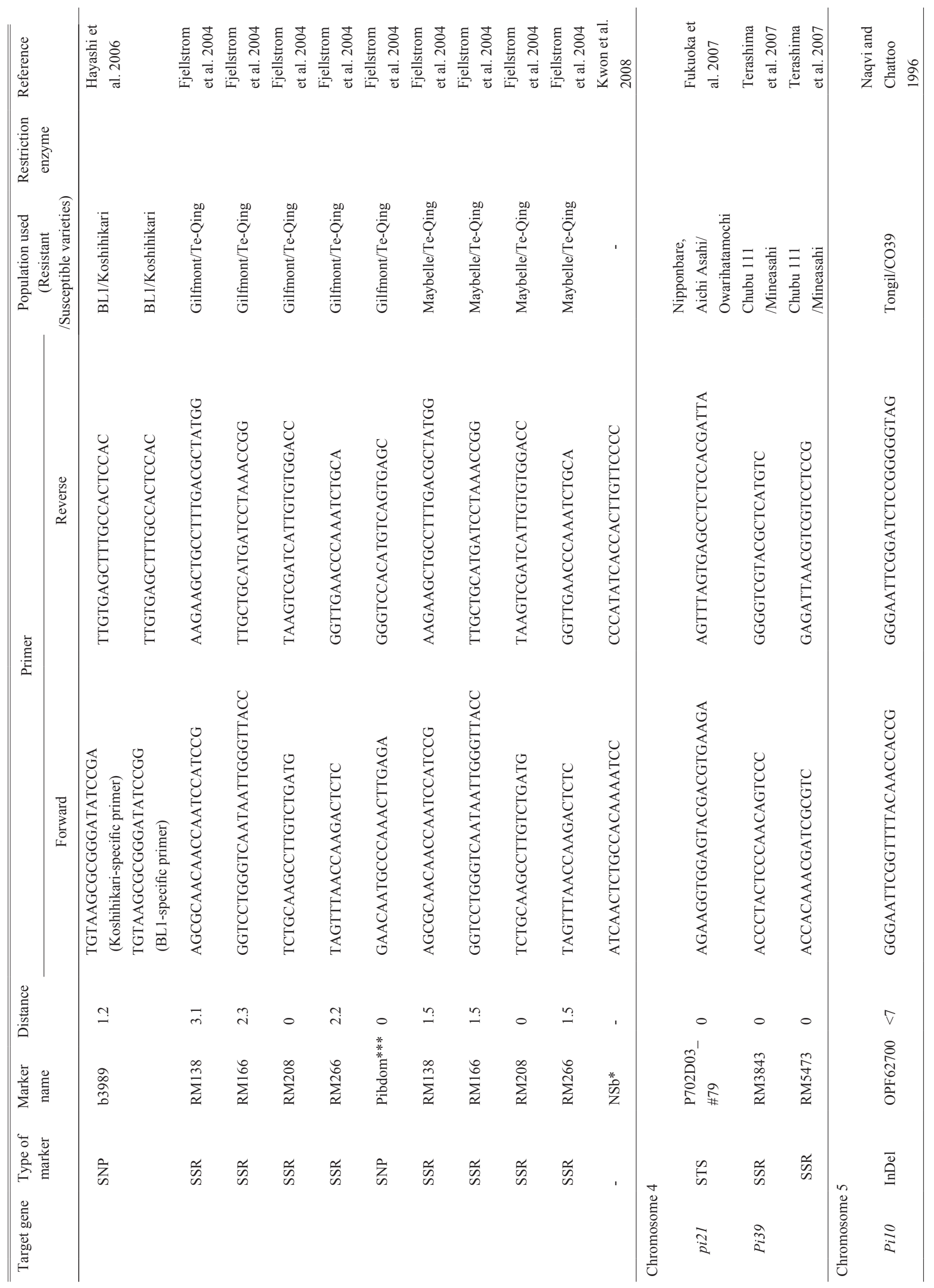




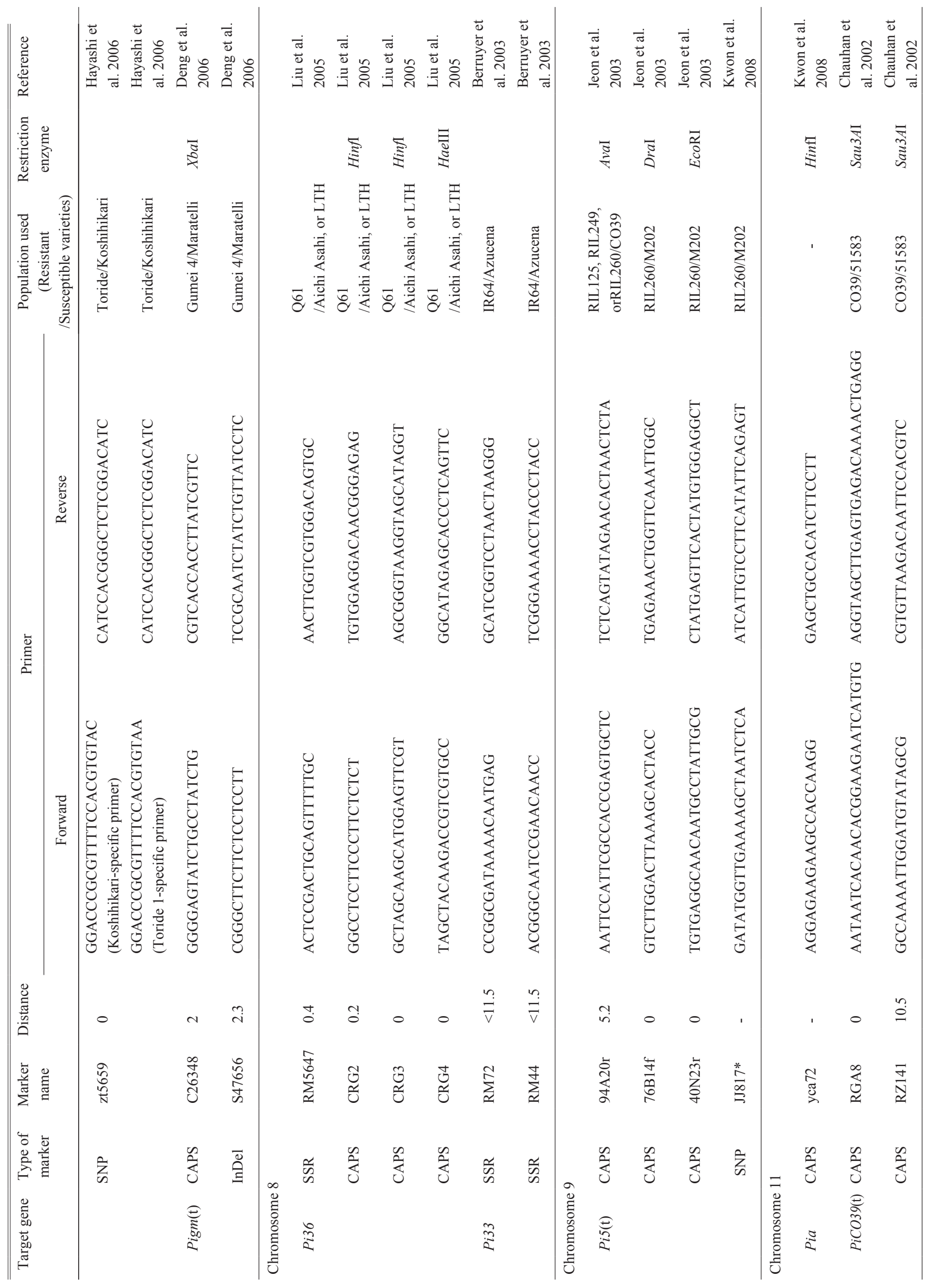




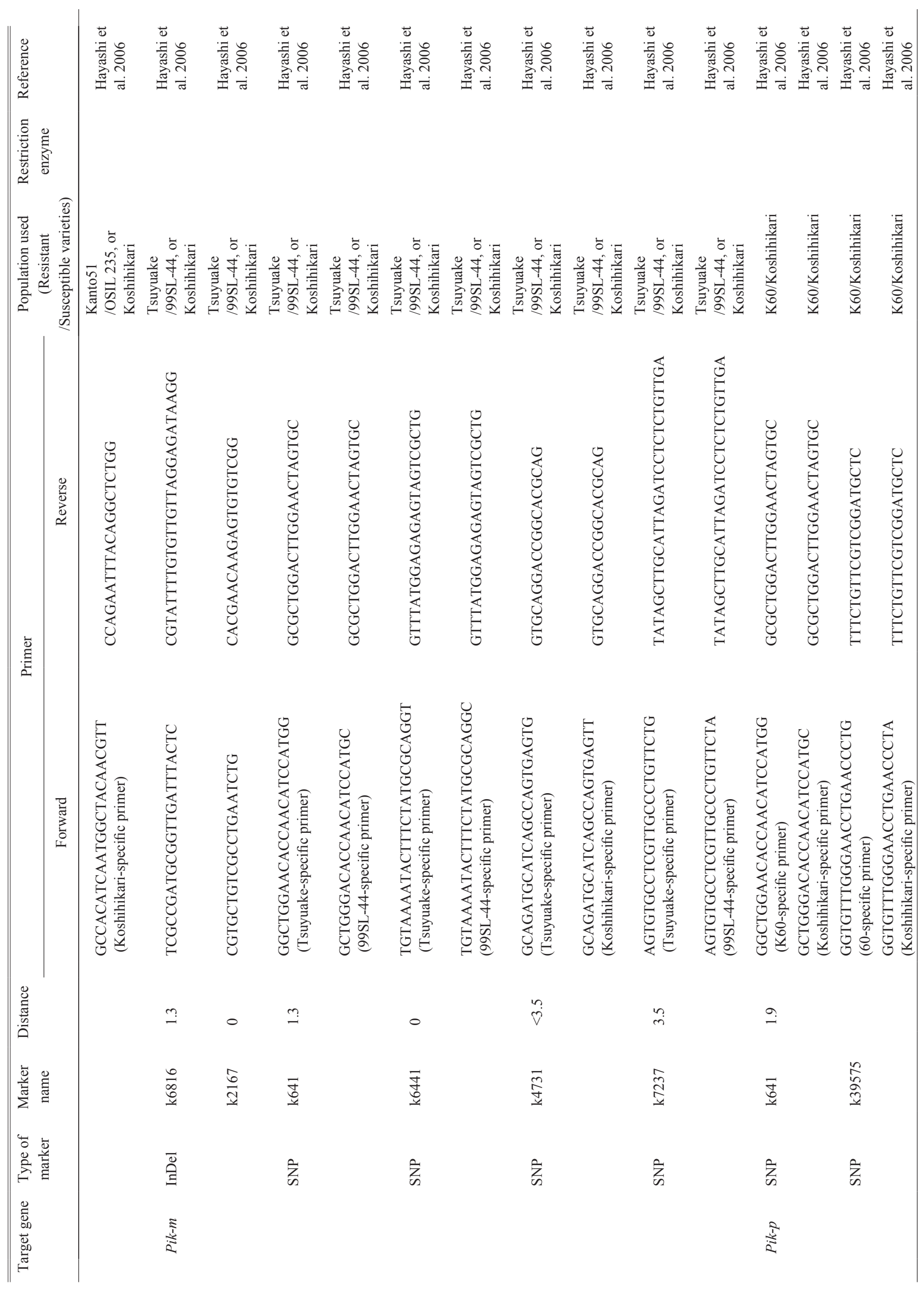




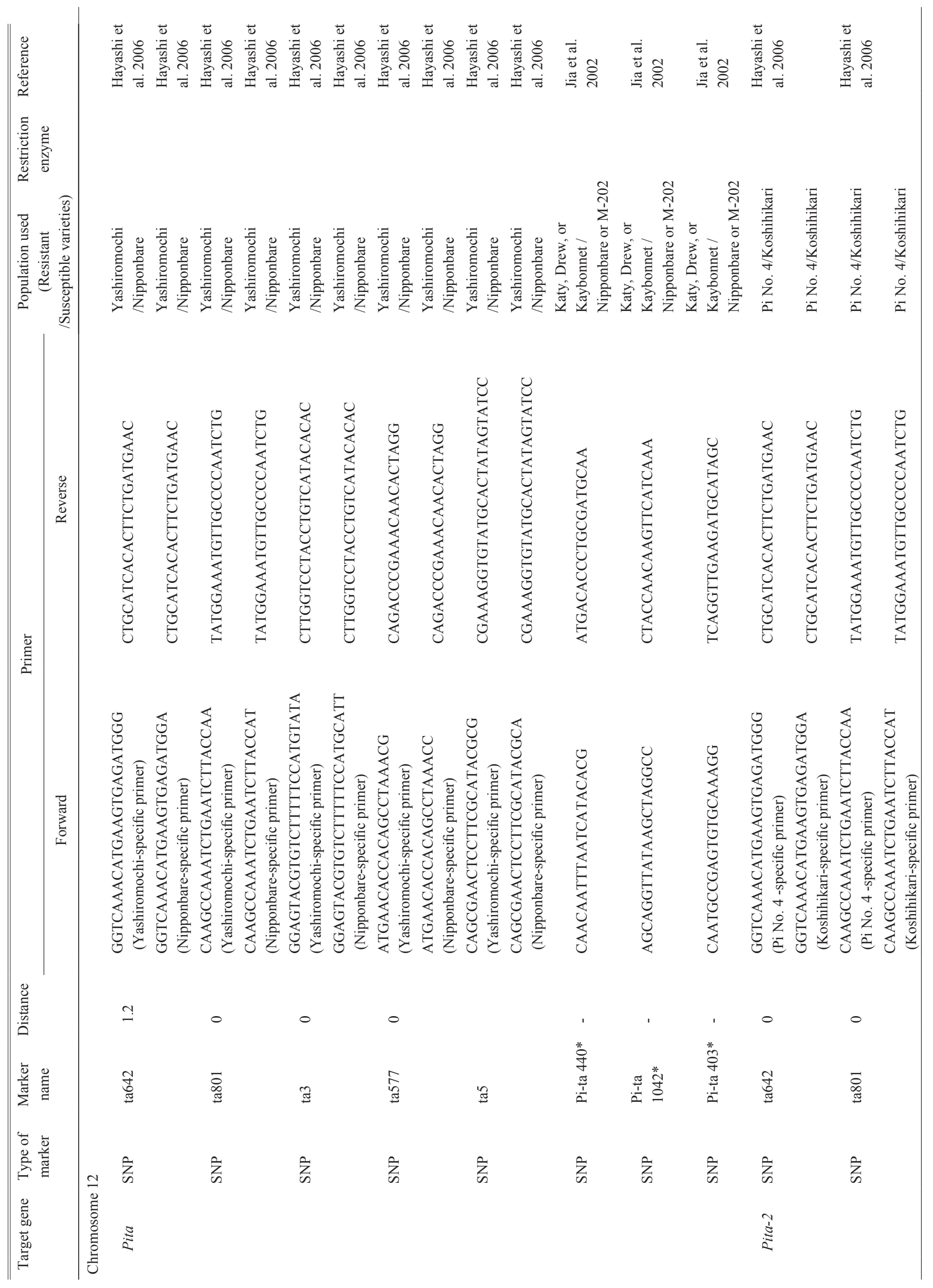


Resistance Genes and Selection Markers for Blast Disease in Rice

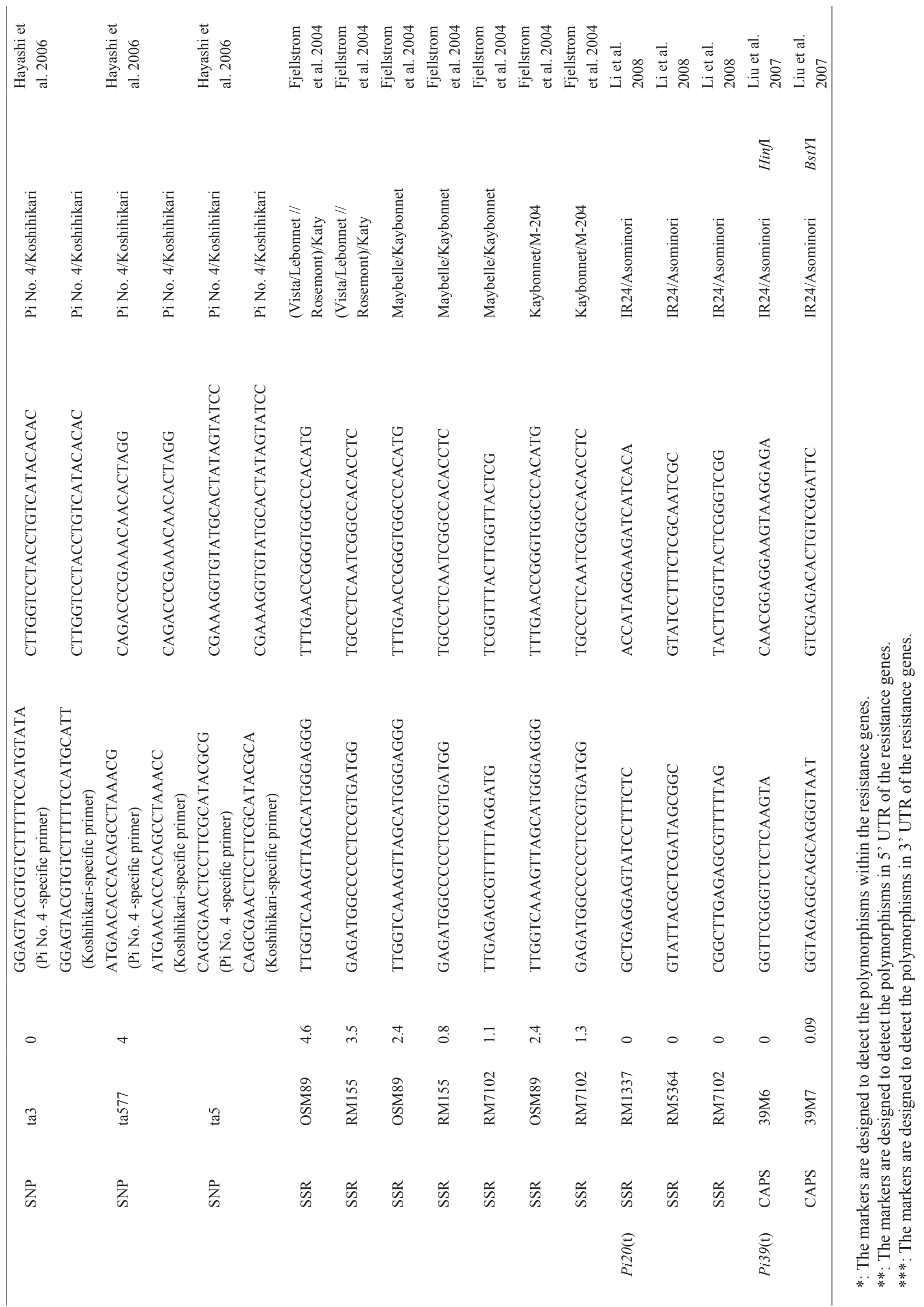


marker that can distinguish the polymorphism underlying the phenotypic effect of the gene (i.e., gene specific marker or functional marker), such a marker has strong association with the phenotype (McCouch et al. 2007). Although there have been many reports of conventional markers for rice blast resistance genes (Table 2), almost all reported markers are linked to the resistance genes (i.e., linkage marker) and there are few gene specific markers reported $^{18,39,52,59}$. Since such linkage markers have weaker association with phenotype than gene specific markers, there are a few limitations on applying them to MAS as discussed below. Thus breeders should use them as a support tool for conventional phenotypic selection.

\section{Recombination between markers and genes}

Association between the linkage markers and the genes is mainly dependent on the genetic distance between them. In general, the association becomes stronger when more tightly linked markers are used However, even though the marker is tightly linked to the gene, recombination between them will possibly occur during the breeding procedure using MAS (as discussed by Fjellstorm et al. ${ }^{18}$ about the relationship between the marker, Pibdom, and the gene, $P i b$ ). If recombination occurs, there will be no association between the marker and the phenotype and, thus, it will be impossible to select the phenotype by that marker. As a result, the plant that does not harbor the target gene may be selected as a false positive. To reduce the possibility of a false positive selection, it is necessary to confirm the introgression of the genetic region where the target gene is by using the gene specific marker or two linkage markers which are on both sides of the flanking region of the gene.

\section{Linkage drag}

Even if one can confirm the introgression of the target genetic region by two linkage markers, another problem of the linkage drag still remains ${ }^{15,41}$. When the linkage marker is used to introduce the resistance gene from the donor strain, not only the resistance gene, but also the chromosomal fragment between the resistance gene and linkage markers is inevitably introduced. Thus there is a probability that the undesirable genes on the chromosome of the donor strain are introduced together with the resistance genes.

\section{Limitation for the universality of the markers}

One of the big issues is knowing whether one marker set designed for a specific cross or population can be applied to other crosses or populations. Because the polymorphisms detected in linkage marker systems do not affect the phenotype of the target gene, such polymorphisms do not always exist between resistance and susceptible strains. Therefore, one marker set which is useful in a specific cross combination does not always work well in other cross combinations. Although several reports showed that linkage markers can be successfully used to screen for varieties with resistance to rice blast ${ }^{18,101,107}$, almost all markers have never been evaluated as to whether they can be applied to other cross combinations. Information about the markers and their applicability to the combinations of the strains will be valuable for rice breeding using MAS.

\section{Conclusion}

Recent progress in rice genomics has facilitated finding new resistance genes in blast disease. The volume of publications identifying new resistance genes will increase in this era of genomics. To avoid confusion, it will be necessary to characterize the resistance genes and organize information about them in an easily understandable format.

For gene characterization, a differential system for rice blast is essential. In the IRRI-Japan Collaborative Research Project, we released the monogenic lines and have been developing NILs together with markers for MAS for blast resistance genes. These lines will be useful not only as gene sources for breeding blast resistance but also as sets of international standard differential varieties used for characterizing the resistance genes. As the number of resistance genes increases, the number of their selection markers applicable to MAS will increase in the future. To enhance the utilization of the selection markers in MAS, it is also necessary to integrate marker information into an easily utilizable database. In this report, we assembled the reported markers for the rice blast resistance genes. This information will encourage the application of MAS in rice breeding programs.

\section{Acknowledgments}

This study was carried out under the IRRI-JAPAN collaborative project, which was supported by the Ministry of Agriculture, Forestry and Fisheries of Japan, and a JIRCAS research project "Blast Research Network for Stable Rice Production”.

\section{References}

1. Ahn, S. N. et al. (1996) Molecular mapping of a gene for resistance to a Korean isolate of rice blast. Rice Genet. Newsl., 13, 74.

2. Ballini, E. et al. (2008) A genome-wide meta-analysis of 
rice blast resistance genes and quantitative trait loci provides new insights into partial and complete resistance. Mol. Plant Microbe In., 21, 859-868.

3. Barman, S. R. et al. (2004) Identification of a major blast resistance gene in the rice cultivar 'Tetep'. Plant Bleed., 123, 300-302.

4. Bent, A. F. (1996) Plant disease resistance genes, function meets structure. Plant Cell, 8, 1757-1771.

5. Berruyer, R. et al. (2003) Identification and fine mapping of Pi33, the rice resistance gene corresponding to the Magnaporthe grisea avirulance gene ACE1. Theor. Appl. Genet., 107, 1139-1147.

6. Bonman, J. M. \& Mackill, D. J. (1988) Durable resistance to rice blast disease. Oryza, 25, 103-110.

7. Bryan, G. T. et al. (2000) A single amino acid difference distinguishes resistant and susceptible alleles of the rice blast resistance gene Pi-ta. Plant Cell, 12, 2033-2045.

8. Causse, M. A. et al. (1994) Saturated molecular map of the rice genome based on an interspecific backcross population. Genetics, 138, 1251-1274.

9. Chauhan, R. S. et al. (2002) Genetic and physical mapping of a rice blast resistance locus, $\mathrm{Pi}$-CO39(t), that corresponds to the avirulence gene AVR1-CO39 of Magnaporthe grisea. Mol. Genet. Genomics, 267, 603-612.

10. Chen, D. H. et al. (1999) Molecular mapping of the blast resistance gene, $P i 44(\mathrm{t})$, in a line derived from a durably resistant rice cultivar. Theor. Appl. Genet., 98, 1046-1053.

11. Chen, S. et al. (2005) Genetic and physical mapping of $P i 37(t)$, a new gene conferring resistance to rice blast in the famous cultivar St. No. 1. Theor. Appl. Genet., 111, $1563-1570$.

12. Chen, X., Cho, Y. \& McCouch, S. R. (2002) Sequence divergence of rice microsatellites in Oryza and other plant species. Mol. Genet. Genomics, 268, 331-343.

13. Chen, X. W. et al. (2004) Identification of two blast resistance genes in a rice variety, Digu. J. Phytopathol., 152, 77-85.

14. Chen, X. et al. (2006) A B-lectin receptor kinase gene conferring rice blast resistance. Plant J., 46, 794-804.

15. Collard, B. C. Y. et al. (2008) Rice molecular breeding laboratories in the genomics era: Current status and future considerations. Int. J. Plant Genomics, doi: $10.1155 / 2008 / 524847$.

16. Deng, Y. et al. (2006) Genetic characterization and fine mapping of the blast resistance locus Pigm( $(t)$ tightly linked to $P i 2$ and $P i 9$ in a broad-spectrum resistant Chinese variety. Theor. Appl. Genet., 113, 705-713.

17. Feltus, F. A. et al. (2004) An SNP resource for rice genetics and breeding based on subspecies indica and japonica genome alignments. Genome Res., 14, 1812-1819.

18. Fjellstrom, R. et al. (2004) Development of DNA markers suitable for marker assisted selection of three $P i$ genes conferring resistance to multiple Pyricularia grisea pathotypes. Crop Sci., 44, 1790-1798.

19. Fujii, K. et al. (1995) Genetical mapping based on the RFLP analysis for the panicle blast resistance derived from a rice parental line St. No. 1. Breed. Sci., 45 (Suppl. 1), 209 [In Japanese].

20. Fujii, K. et al. (2000) Identification of a RFLP marker tightly linked to the panicle blast resistance gene, $P b 1$, in rice. Breed. Sci., 50, 183-188.

21. Fukuoka, S. \& Okuno, K. (2001) QTL analysis and mapping of pi21 a recessive gene for field resistance to rice blast in Japanese upland rice. Theor. Appl. Genet., 103, 185-190.

22. Fukuoka, S. et al. (2005) Genetic dissection of resistance to rice blast for rice germplasm enhancement. $10^{\text {th }}$ International Congress of SABRAO Proceedings, S-2.

23. Fukuoka, S., Okuno, K. \& Kawase, M. (2007) Rice blast disease gene $P i 21$, resistance gene pi21 and utilization thereof. Patent WO/2007/000880

24. Fukuta, Y. et al. (2004) Quantitative trait loci (QTL) reactions to rice blast isolates from Japan and the Philippines. In Rice blast: Interaction with rice and control, ed. Kawasaki, S., Kluwer Academic Pub., 113-121.

25. Fukuta, Y. et al. (2004) Development of differential variations for blast resistance in IRRI-Japan collaborative research project. In Rice blast: Interaction with rice and control. ed. Kawasaki, S., Kluwer Academic Pub., 229-233.

26. Glaszmann, J. C. (1987) Isozymes and classification of Asian rice varieties. Theor. Appl. Genet., 74, 21-30.

27. Goto, I. (1970) Genetic studies on the resistance of rice plant to the blast fungus I. Inheritance of resistance in crosses Sensho x H-79 and Imochishirazu x H-79. Ann. Phytopath. Soc. Japan, 36, 304-312.

28. Goto, I. (1976) Genetic studies on resistance of rice plant to blast fungus II. Difference in resistance to the blast disease between Fukunishiki and its parental cultivar, Zenith. Ann. Phytopath. Soc. Japan, 42, 253-260.

29. Goto, I. (1988) Genetic studies on resistance of rice plant to blast fungus (VII). Blast resistance genes of Kuroka. Ann. Phytopath. Soc. Japan, 54, 460-465 [In Japanese with English summary].

30. Goto, I., Jaw, Y. L. \& Baluch, A. A. (1981) Genetic studies on resistance of rice plant to blast fungus IV. Linkage analysis of four genes, Pi-a, Pi-k, Pi-z and Pi-i. Ann. Phytopath. Soc. Japan, 47, 252-254.

31. Gowda, M., Roy-Barman, S. \& Chattoo, B. B. (2006) Molecular mapping of a novel blast resistance gene Pi38 in rice using SSLP and AFLP markers. Plant Breed., 125, 596-599.

32. Hammond-Kosack, K. E. \& Jones, J. D. G. (1997) Plant disease resistance genes. Ann. Rev. Plant Physiol. Plant Mol. Biol., 48, 575-607.

33. Harushima, Y. et al. (1998) A high-density rice genetic linkage map with 2275 markers using a single $\mathrm{F} 2$ population. Genetics, 148, 479-494.

34. Hashimoto, N. et al. (1998) Selection of individual having $P i-z$, the rice blast true resistance gene, using RFLP markers in resistance sensitive cross progeny. Breed. Sci., $\mathbf{4 8}$ (Suppl. 2), 109 [In Japanese].

35. Hayasaka, H. et al. (1996) RFLP mapping of a rice blast resistance gene Pi-k. Breed. Sci., 46 (Suppl. 2), 68 [In Japanese].

36. Hayasaka, H. et al. (1995) RFLP mapping of a rice blast resistance gene Pi-b. Breed. Sci., 45 (Suppl. 1), 92 [In Japanese].

37. Hayashi, N., Ando, I. \& Naito, H. (1996) Gene analysis of a new blast resistance in the paddy rice variety, Aichi Asahi. Breed. Sci., 46 (Suppl. 2), 168 [In Japanese].

38. Hayashi, N., Ando, I. \& Imbe, T. (1998) Identification of 
a new resistance gene to a Chinese blast fungus isolate in the Japanese rice cultivar Aichi Asahi. Phytopathology, 88, 822-827.

39. Hayashi, K., Yoshida, H. \& Ashikawa, I. (2006) Development of PCR-based allele specific and InDel marker sets for nine rice blast resistance genes. Theor. Appl. Genet., 113, 251-260.

40. Hittalmani, S. et al. (2000) Fine mapping and DNA markerassisted pyramiding of the three major genes for blast resistance in rice. Theor. Appl. Genet., 100, 1121-1128.

41. Hospital, F. (2001) Size of donor chromosome segments around introgressed loci and reduction of linkage drag in marker-assisted backcross programs. Genetics, 158, 1363-1379.

42. Hulbert, S. H. et al. (2001) Resistance gene complexes, evolution and utilization. Ann. Rev. Phytopath., 39, 285312 .

43. Imbe, T. \& Matsumoto, S. (1985) Inheritance of resistance of rice varieties to the blast fungus strains virulent to the variety "Reiho". Jpn. J. Breed., 35, 332-339 [In Japanese].

44. Imbe, T. et al. (1997) A new gene for blast resistance in rice cultivar, IR 24. Rice Genet. Newsl., 14, 60-62.

45. Inukai T. et al. (1996) Genetic analysis of blast resistance in tropical rice cultivars using near-isogenic lines. In Rice genetics III, Proceeding of the third international rice genetics symposium, ed. Khush, G. S., International Rice Research Institute, Manila (Philippines), 447-455.

46. Ise, K. (1991) Linkage analysis of some blast resistance gene in rice, Oryza sativa L. Jpn J. Breed., 42 (Suppl. 2), 388-389 [In Japanese].

47. Iwata, N. (1996) Registration of new gene symbols. Rice Genet. Newsl., 13, 12-18.

48. Iwata, N. (1997) Registration of new gene symbols. Rice Genet. Newsl., 14, 9-11.

49. Jeon, J. S. et al. (2003) Genetic and physical mapping of Pi5(t), a locus associated with broad-spectrum resistance to rice blast. Mol. Genet. Genomics, 269, 280-289.

50. Jeung, J. U. et al. (2007) A novel gene, Pi40(t), linked to the DNA markers derived from NBS-LRR motifs confers broad spectrum of blast resistance in rice. Theor. Appl. Genet., 115, 1163-1177.

51. Jia, Y. et al. (2000) Direct interaction of resistance gene and avirulence gene products confers rice blast resistance. EMBO J., 19, 4004-4014.

52. Jia, Y., Wang, Z. \& Singh, P. (2002) Development of dominant rice blast $\mathrm{Pi}$-ta resistance gene markers. Crop Sci., $\mathbf{4 2}$, 2145-2149.

53. Kaji, R. \& Ogawa, T. (1996) RFLP mapping of a blast resistance gene, $\mathrm{Pi}-k^{m}$, in rice. Breed. Sci., 46 (Suppl. 1), 70 [In Japanese].

54. Kinoshita, T., Inukai, T. \& Toriyama, K. (1994) Reports form coordinators; gene symbols for blast resistance newly revised. Rice Genet. Newsl., 11, 16-17.

55. Kinoshita, T. \& Kiyosawa, S. (1997) Some considerations on linkage relationships between Pii and Piz in the blast resistance of rice. Rice Genet. Newsl., 14, 57-59.

56. Kiyosawa, S. \& Murty, V. V. S. (1969) The inheritance of blast-resistance in Indian rice variety, HR-22. Jpn. J. Breed., 19, 269-276.

57. Koizumi, S. (2007) Durability of resistance to rice blast disease. In JIRCAS working report no. 53, eds. Fukuta, Y., Vera Cruz, C. M. \& Kobayashi, N., JIRCAS, 1-10.

58. Kobayashi, N. et al. (2007) Development of new sets of International standard differential varieties for blast resistance in rice (Oryza sativa L.). JARQ, 41(1), 31-37.

59. Kwon, S. W. et al. (2008) Development of near-isogenic Japonica rice lines with enhanced resistance to $\mathrm{Mag}$ naporthe grisea. Mol. Cells, 25, 407-416.

60. Lattterell, F. M. \& Rossi, A. E. (1986) Longevity and pathogenic stability of Pyricularia oryzae. Phytopathology, 76, 231-235.

61. Lei, C. L. et al. (2005) Molecular mapping of a blast resistance gene in an indica rice cultivar Yanxian No. 1. Rice Genet. Newsl., 22, 76-77.

62. Li, L. Y. et al. (2007) The $P i k^{m}$ gene, conferring stable resistance to isolates of Magnaporthe oryzae, was finely mapped in a crossover-cold region on rice chromosome 11. Mol. Breed., 20, 179-188.

63. Li, W. et al. (2008) Identification of SSR markers for a broad-spectrum blast resistance gene Pi20(t) for markerassisted breeding. Mol. Breed., 22, 141-149.

64. Lin, F. et al. (2007) The blast resistance gene Pi37 encodes a nucleotide binding site-leucine-rich repeat protein and is a member of a resistance gene cluster on rice chromosome 1. Genetics, 177, 1871-1880.

65. Liu, B. et al. (2004) Candidate defense genes as predictors of quantitative blast resistance in rice. Mol. Plant Microbe In., 17, 1146-1152.

66. Liu, X. et al. (2007) The in silico map-based cloning of Pi36, a rice coiled-coil-nucleotide-binding site-leucinerich repeat gene that confers race-specific resistance to the blast fungus. Genetics, 176, 2541-2549.

67. Liu, X. et al. (2007) Identification and fine mapping of Pi39(t), a major gene conferring the broad-spectrum resistance to Magnaporthe oryzae. Mol. Genet. Genomics, 278, 403-410

68. Liu, X. Q. et al. (2005) Genetic and physical mapping of Pi33(t), a novel rice blast resistance gene located on rice chromosome 8. Mol. Genet. Genomics, 274, 394-401.

69. McCouch, S. R. et al. (1994) Mapping of blast resistance genes in rice. In Rice blast disease, eds. Zeigler, R. S., Leong, S. A. \& Teng, P. S., C.A.B. International, Wallingford, UK, 167-186.

70. McCouch, S. R. et al. (2007) Through the genetic bottleneck: $O$. rufipogon as a source of trait-enhancing alleles for O. sativa. Euphytica, 154, 317-339.

71. Mohan, M. et al. (1997) Genome mapping, molecular markers and marker-assisted selection in crop plants. Mol. Breed., 3, 87-103.

72. Monosi, B. et al. (2004) Full-genome analysis of resistance gene homologues in rice. Theor. Appl. Genet., 109 , 1434-1447.

73. Nakamura, S. et al. (1997) Construction of an 800-kb contig in the near-centromeric region of the rice blast resistance gene $P i$ - $t a^{2}$ using a highly representive rice $\mathrm{BAC}$ library. Mol. Gen. Genet., 254, 611-620.

74. Naqvi, N. I. \& Chattoo, B. B. (1996) Molecular genetic analysis and sequence characterized amplified region-assisted selection of blast resistance in rice. In Rice genetics III. Proceeding of the third international rice genetics symposium, ed. Khush, G. S., International Rice Research 
Institute, Manila (Philippines), 570-576.

75. Naqvi, N. I. \& Chattoo, B. B. (1996) Development of a sequence characterized amplified region (SCAR) based indirect selection method for a dominant blast-resistance gene in rice. Genome, 39, 26-30.

76. Naqvi, N. I. et al. (1995) Identification of RAPD markers linked to a major blast resistance gene in rice. Mol. Breed., 1, 341-348.

77. Nasu, S. et al. (2002) Search for and analysis of single nucleotide polymorphisms (SNPs) in rice (Oryza sativa, Oryza rufipogon) and establishment of SNP markers. DNA Res., 9, 163-171.

78. Nguyen, T. T. T. et al. (2006) Pi35(t), a new gene conferring partial resistance to leaf blast in the rice cultivar Hokkai 188. Theor. Appl. Genet., 113, 697-704.

79. Ou, S. H. (1985) Rice Diseases, $2^{\text {nd }}$ ed. Commonwealth Mycological Institute Kew, UK, pp.380.

80. Pan, Q. H., Tanisaka, T. \& Ikehashi, H. (1995) Studies on the genetics and breeding of blast resistance in rice IV. Gene analysis for the blast resistance of a indica variety Kasalath. Breed. Sci., 45 (Suppl. 2), 170 [In Japanese].

81. Pan, Q. H. et al. (1996) Studies on the genetics and breeding of blast resistance in rice V. Identification of two blast resistance genes in a Yunnan native variety, Maowangu. Breed. Sci., 46 (Suppl. 1), 79.

82. Pan, Q. H., Tanisaka, T. \& Ikehashi, H. (1996) Studies on the genetics and breeding of blast resistance in rice VI. Gene analysis for the blast resistance of two Yunnan native cultivars GA20 and GA25. Breed. Sci., 46 (Suppl. 2), 70 [In Japanese].

83. Pan, Q. H., Tanisaka, T. \& Ikehashi, H. (1997) Studies on the genetics and breeding of blast resistance in rice VII. Gene analysis for the blast resistance of Indian native cultivar, Aus 373. Breed. Sci., 47 (Suppl. 1), 35 [In Japanese].

84. Pan, Q. H. et al. (2003) Fine mapping of the blast resistance gene Pi15, linked to Pii on rice chromosome 9. Acta Bot. Sinica, 45, 871-877.

85. Pan, Q. et al. (1996) Identification of a new blast resistance gene in the indica rice cultivar Kasalath using Japanese differential cultivars and isozyme markers. Phytopathology, 86, 1071-1075.

86. Parlevliet, J. E. (1979) Components of resistance that reduce the rate of epidemic development. Ann. Rev. Phytopath., 17, 203-222.

87. Qu, S. et al. (2006) The broad-spectrum blast resistance gene $P i 9$ encodes a nucleotide-binding site-leucine-rich repeat protein and is a member of a multigene family in rice. Genetics, 172, 1901-1914.

88. Sallaud, C. et al. (2003) Identification of five new blast resistance genes in the highly blast-resistant rice variety IR64 using a QTL mapping strategy. Theor. Appl. Genet., 106, 794-803.

89. Sasaki, R. (1923) Existence of strains in rice blast fungus II. J. Plant Pro., 10, 1-10.

90. Sharma, T. R. et al. (2005) High-resolution mapping, cloning and molecular characterization of the $P i-k^{h}$ gene of rice, which confers resistance to Magnaporthe grisea. Mol. Genet. Genomics, 274, 569-578.

91. Shinoda, H. et al. (1971) Studies on the varietal resistance of rice to blast. 6. Linkage relationship of blast resistance genes. Bull. Chugoku Agric. Exp. St. Ser. A, 20, 1-25 [In
Japanese].

92. Tabien, R. E. et al. (2000) Mapping of four major rice blast resistance genes from 'Lemont' and 'Teqing' and evaluation of their combinatorial effect for field resistance. Theor. Appl. Genet., 101, 1215-1225.

93. Tabien, R. E. et al. (2002) Mapping QTLs for field resistance to the rice blast pathogen and evaluating their individual and combined utility in improved varieties. Theor. Appl. Genet., 105, 313-324.

94. Tanksley, S. D. et al. (1989) RFLP mapping in plant breeding: New tools for an old science. Biotechnology (N. Y.) 7 , 257-263.

95. Telebanco-Yanoria, M. J. T. et al. (2008) Diversity analysis for resistance of rice (Oryza sativa L.) to blast disease [Magnaporthe grisea (Hebert) Barr.] using differential isolates from the Philippines. Plant Breed., 127, 355-363.

96. Telebanco-Yanoria, M. J. et al. (2008) A set of standard differential blast isolates (Pyricularia grisea (Cooke) Sacc.) from the Philippines for rice (Oryza sativa L.) resistance. $J A R Q, 42,23-34$.

97. Terashima, T. et al. (2008) Mapping of a blast field resistance gene $P i 39(t)$ of elite rice strain Chubu 111. Plant Breed., 127, 485-489, doi:10.1111/j.14390523.2007.01451.x.

98. Toriyama, K. et al. (1983) A method of estimating true resistance genes to blast in rice varieties by testing their backcrossed progenies for rice-specific reactions. Jpn. J. Breed., 33, 448-456.

99. Tsunematsu, H. et al. (2000) Development of monogenic lines of rice for blast resistance. Breed. Sci., 50, 229234.

100. Wang, G. L. et al. (1994) RFLP mapping of genes conferring complete and partial resistance to blast in a durably resistant rice cultivar. Genetics, 136, 1421-1434.

101. Wang, Z. et al. (2007) Rapid survey for presence of a blast resistance gene $P i$ - $t a$ in rice cultivars using the dominant DNA markers derived from portions of the Pi-ta gene. Plant Breed., 126, 36-42.

102. Wang, Z. X. et al. (1999) The Pib gene for rice blast resistance belongs to the nucleotide binding and leucine-rich repeat class of plant disease resistance genes. Plant J., 19, $55-64$.

103. Wu, J. L. et al. (2005) Genetic control of rice blast resistance in the durably resistant cultivar Gumei 2 against multiple isolates. Theor. Appl. Genet., 111, 50-56.

104. Wu, K. S. et al. (1996) Cloning a blast resistance gene by chromosome walking. In Rice genetics III. Proceeding of the third international rice genetics symposium, ed. Khush, G. S., International Rice Research Institute, Manila (Philippines), 669-674.

105. Xu, Y. \& Crouch, J. H. (2008) Marker-assisted selection in plant breeding: From publications to practice. Crop Sci., 48, 391-407.

106. Xu, X. et al. (2008) Efficient authentic fine mapping of the rice blast resistance gene Pik- $h$ in the Pik cluster, using new Pik-h-differentiating isolates. Mol. Breed., 22, 289-299.

107. Yi, G. et al. (2004) Use of Pi5(t) markers in marker-assisted selection to screen for cultivars with resistance to Magnaporthe grisea. Theor Appl. Genetics, 109, 978-985.

108. Yu, J. et al. (2002) A draft sequence of the rice genome (Oryza sativa L. ssp. indica). Science, 296, 79-92. 
109. Yu, J. et al. (2005) The genomes of Oryza sativa: a history of duplications. PLoS Biol., 3, 266-281.

110. Yunoki, T. et al. (1970) Studies on the varietal resistance of rice blast. 4. Variation of field resistance due to fungus strains. Bull. Chugoku Agric. Exp. St., Ser. E, 6, 21-41 [In Japanese].

111. Zenbayashi, K. et al. (2002) Mapping of the QTL (quantitative trait locus) conferring partial resistance to leaf blast in rice cultivar Chubu 32. Theor. Appl. Genet., 104, 547552.

112. Zenbayashi-Sawata, K., Ashizawa, T. \& Koizumi, S. (2005) Pi34-AVRPi34: a new gene-for-gene interaction for partial resistance in rice to blast caused by Magnaporthe grisea. J. Gen. Plant Pathol., 71, 395-401.

113. Zheng, K. L. et al. (1996) Identification of DNA markers tightly linked to blast resistance genes in rice. In Rice genetics III. Proceeding of the third international rice genetics symposium, ed. Khush, G. S., International Rice Research Institute, Manila (Philippines), 565-569.
114. Zhou, B. et al. (2006) The eight amino-acid differences within three leucine-rich repeats between Pi2 and Piz-t resistance proteins determine the resistance specificity to Magnaporthe grisea. Mol. Plant Microbe In., 19, 12161228.

115. Zhou, J. H. et al. (2004) Identification and mapping of a rice blast resistance gene $P i-g(t)$ in the cultivar Guangchangzhan. Plant Pathol., 53, 191-196.

116. Zhu, M., Wang, L. \& Pan, Q. (2004) Identification and characterization of a new blast resistance gene located on rice chromosome 1 through linkage and differential analyses. Phytopathology, 94, 515-519.

117. Zhuang, J. Y. et al. (1997) Genetic analysis of the blast resistance gene at vegetative and reproductive stages in rice. Rice Genet. Newsl., 14, 62-64.

118. Zhuang, J. Y. et al. (2001) Genetic drag between a blast resistance gene and QTL conditioning yield trait detected in a recombinant inbred line population in rice. Rice Genet. Newsl., 18, 69-70. 